closed treatment and not a justifiable substitute for the latter method. Rigid internal fixation of the tibia should be regarded as an elective operation-to be done by the experienced fracture surgeon using an atraumatic technique. The immediate internal fixation of a fresh tibial shaft fracture should not be routine; early internal fixation delays healing and is surgically unsafe. The risk of serious infection is unacceptably high. Closed treatment is therefore the method of choice for most of these injuries.

\section{References}

${ }^{1}$ Nichol, E A, fournal of Bone and foint Surgery, 1964, 46B, 373.

${ }^{2}$ Muller, M E, Proceedings of the Royal Society of Medicine, 1963, 56, 455.

${ }^{3}$ Smith, J E M, Fournal of Bone and foint Surgery, 1974, 56B, 469.

${ }^{4}$ Hicks, J H, Injury, 1971, 3, 121.

${ }^{5}$ Olerud, S, and Karlström, G, Acta Orthopaedica Scandinavica, 1972, Suppl 140.

${ }^{6}$ Wade, P A, fournal of Trauma, 1970, 10, 513

\title{
A case of haematuria
}

\author{
R T W PRENTICE, J D FERGUSSON
}

British Medical fournal, 1977, 1, 155-157

\section{The trainee's problem}

It took her several days to summon up courage to consult me about the blood she had passed in her urine. In fact, it perhaps took two years, as this was the second time it had happened, on both occasions with symptoms suggesting concurrent infection. This more recent episode occurred after having intercourse with her husband for the first time for over six months. When I saw her a week afterwards she was symptom-free, and it was difficult to ascertain whether the blood had been from the bladder or from elsewhere in the urinary tract. The urine culture was sterile and blood was absent from the urine.

The patient is 53 and seems basically happy but anxious. Her mother died recently after needing home nursing because of a hemiplegia and she had coped much better than anyone thought she could. She has two outstanding fears-one of hospital and investigation and the other of malignant disease. Unfortunately the latter has been heightened by her sister dying of cancer (she doesn't know of what) two years ago. The patient had a hysterectomy for fibroids 12 years ago; at least in part I think this operation was eventually precipitated by her fear of malignancy and it aggravated her other fear-that of again needing investigation or surgery.

I realise that she has probably nothing seriously wrong but find she is putting too much pressure on me to guarantee she has "nothing to worry about." Should I protect myself by referring her to hospital or should I be referring all patients with haematuria in any case? And can I reasonably ask the consultant to restrict what investigations he does in order not to upset the patient?

\section{General practitioner's comments}

The problem here, to some extent, is that the doctor's faith in his clinical judgment is disturbed by the patient's fears of more

Bearsden, Glasgow G61 2DN

R T W PRENTICE, MB, MRCP GLAS, general practitioner

St Peter's Hospitals, London WC2A 2EX

J D FERGUSSON, MD, FRCS, honorary consultant surgeon serious underlying diseases and her anxiety about possible hospital investigation. He admits to too much pressure being put upon him to guarantee her safety and that his principal reason for referring her might be merely to protect himself.

Close examination of the history shows that this is the second episode and that the initial episode of haematuria was about two years ago. Another aspect suggestive of a benign underlying cause is the association with symptoms suggesting concurrent urinary infections. The patient herself, however, may not have properly identified the source of the bleeding. She came to the doctor a week later, when there were no symptoms and when her urine was found to be sterile and free of blood. There is no way of being certain, for example, that the blood was not primarily vaginal in origin. There is a little evidence to support this possibility in the relationship of the haematuria with intercourse. This latter aspect introduces the additional possibility that this was urethritis. If a differential diagnosis were constructed here urinary tract infection should be considered first, then urethritis and menopausal vaginitis.

Some preliminary investigations could be carried out by the doctor himself to eliminate these possibilities. He has already examined the urine, and this should be repeated on several occasions and a bacterial count requested. Careful vaginal examination and assessment of the vaginal mucosa are indicated. Further investigation of the urinary tract by intravenous pyelography could be carried out if open access facilities are available. When he has completed these investigations he will not have confirmed his patient's fear that to consult her doctor about such a symptom is to invite an immediate referral to hospital and to specialist investigation. Instead he will have, perhaps, built up her confidence in him as a primary care physician, and this can only benefit her relation with the practice in future.

\section{CLINICAL APPROACH}

Probably the patient is somewhat depressed after the recent death of her mother from a lengthy illness. We know of her fear of cancer, now heightened by the death of her sister only two years ago. A firm but sympathetic approach will be necessary to deal with her present problem within the practice. At the same time an opportunity to ventilate her depressive symptoms and anxieties may be therapeutic. A much more serious symptom could be suppressed in the future, if she were to assume that consultation with her doctor resulted in immediate referral to 
hospital. These investigations, however, may show that this haematuria is not caused by one or other of those benign conditions. For example, the doctor might continue to find red cells in the urine without symptoms, a persistent pyuria, or an intravenous pyelogram might show a filling defect in the bladder. In this case, referral for specialist opinion and further investigation would be mandatory.

The likelihood of referral being necessary in this particular case is not high, and there is much to be gained by not adopting this course too early. On finding that further specialist investigation is necessary, the doctor is in a much better position to reassure the patient before her outpatient appointment. He has, by this time, a much clearer idea of the likely course of events, thus affording him the opportunity to explain those to her calmly and in some detail in his own familiar consulting room. I think that it is quite unfair for the doctor to request that the consultant restrict his investigations. He must make up his mind whether he has to refer, and having referred her it is unreasonable of him to attempt to influence unduly the consultant's approach. This may put the consultant in an invidious position and potentially interfere with his role, which is to give an authoritative opinion based on further investigation.

In general terms, I would regard it as the general practitioner's responsibility to carry out preliminary investigation of his patients presenting with haematuria, particularly female. The patients with painless haematuria, particularly male, will, however, require specialist investigation. Provided one is always alert to the possibility that haematuria is a presenting symptom of a serious underlying disease, it is nevertheless my experience in general practice that the causes of haematuria are usually simple-infection and calculi being the commonest.

\section{Consultant's comments}

It is easy to appreciate the problems posed by this particular case of transient haematuria, especially in view of the psychological aspects. On the one hand, the occurence of bleeding must have aroused enough anxiety in this patient to warrant a visit to her practitioner, if only in the hope that reassurance and simple treatment might suffice, whereas the possible need for more detailed investigation may not have been so clearly envisaged. It is in such cases that the general practitioner assumes an important cole in allaying immediate fears while, at the same time, making a reasoned clinical assessment and paving the way gently for referral to hospital if needed. Obviously in these respects experience counts, and perhaps the following points may help in seeing such cases in perspective.

Generally, the passage of blood in the urine must be regarded as abnormal and noteworthy and, although in this case the circumstances suggest a recurrent transient inflammation of the lower urinary tract (urethrotrigonitis) as the cause, it may be difficult to exclude more serious disease without further clinical information and investigation. Firstly, enough evidence must be obtained to justify the assumption that blood has in fact been, or is being, passed in the urine and that it has not come from some alternative local, perhaps gynaecological, cause. Inquiry as to any ectopic bleeding from other more distant sites may also help to exclude unusual cases with haemorrhagic diathesis. Secondly, the quality and character of the haematuria, whether profuse (with or without clots) or scanty, total or mainly initial or terminal-as well as its association with other urinary symptoms-may help to suggest its origin and probable cause. Thirdly, the question both of intercurrent disease (such as hypertension) and of any physical conditions prevailing at the time (in this case-postcoital) must be taken into account as possible predisposing factors.

\section{CLINICAL EXAMINATION}

Clinical examination should be directed particularly towards the abdomen, pelvis, and external genitalia in addition to a routine study of the urine. In most cases the findings on physical examination will probably prove unhelpful owing to the relative inaccessibility of most of the urinary tract. Apart from the occasional detection of major disease (for instance, renal swellings or bladder distension) its main value lies in excluding local lesions such as urethral caruncle, prolapse, and senile vaginitis as possible causes of bleeding. It must always be remembered, however, that their presence does not necessarily imply that they are responsible, particularly if the clinical history and character of the haematuria suggest additional disease. Examination of the urine is mandatory in all patients presumed to have passed blood and should, in addition to routine examination of a casual specimen, include microscopy and culture in a suitable laboratory. This can usually be easily arranged (as in this case) without the mental anxiety or inconvenience of a hospital visit. It is important, however, when urinary infection is suspected to withhold antibiotics or any form of chemotherapy until after the specimen has been dispatched.

Having obtained and collated all information available on the above lines (as in the current problem), the practitioner must decide on the need for further investigation and referral for a consultant opinion. Generally all cases of undiagnosed haematuria merit expert advice and particularly those when the urine has been totally stained or the bleeding has been recurrent or accompanied by urinary symptoms amounting to more than would reasonably be associated with a transient non-specific lower tract inflammation. In such cases the burden of responsibility becomes too great for the practitioner to continue singlehanded in adopting a course of observation and empirical treatment, so that any objection to seeking a further opinion must be firmly, albeit delicately, overcome in order to safeguard his own position. Admittedly there may be qualifying factors, as in some cases when bleeding has been scanty and intermittent with an accompanying history and symptoms strongly indicative of non-specific ascending urethral infection. Here the experience of the practitioner will prove of value in weighing up the clinical details of the case-particularly in relation to age and sex-and deciding for or against the remote possibility of any more sinister cause. Among the latter must be considered nephrological disorders, specific infections (such as tuberculosis), calculi and, above all, neoplasia, all of which may sometimes present in unorthodox fashion.

\section{PSYCHOLOGICAL ASPECTS}

The remaining facets to be considered before referral to hospital are the psychological attitude and constitutional state of the patient. Usually a reliable second opinion is unlikely to be available without further investigation-including intravenous urography and endoscopic examination-but it is well to remember that, in the event of negative findings, the psychological benefit to the patient may more than compensate for any initial reluctance. Regarding any intercurrent constitutional disease-for example, severe hypertension or senile debilitythe position must be more clearly weighed, since the risks of extended investigation have to be equated against the likely prospects of successful treatment. Nevertheless, a consultant urologist should invariably take such matters into account, particularly after appropriate briefing from the practitioner, and there is no doubt that an explanatory letter would always be welcomed.

As to this individual problem the relevant details relate to the patient's sex and age, her recurrent haematuria, and her psychological aversion to hospital. While it is undoubtedly true that recurrent urinary infection with occasional slight haematuria is common in women, other possibly more serious causes exist, and perhaps particularly so at the age of 53. Moreover, despite the fact that the most recent episode of bleeding followed coitus, its recurrence alone suggests the need for further investigation. Although it may be argued that the interval of two years between the successive attacks suggests that the cause is unlikely to be 
sinister, it cannot be assumed with certainty that the same cause is responsible. I would urge that, after suitable explanation, she should be referred for a consultant's opinion and undoubtedly a confidential letter explaining the details of her case and the desirability of proceeding cautiously towards further investigation would be well received.

\section{Postscript to the problem}

There was division of opinion among the doctors in the practice as to the correct initial management of this patient. Eventually we agreed not to refer but wait and see. Ten days later the same story was presented again, symptoms this time occurring four days after intercourse. This time, after a short discussion, referral was proposed and surprisingly happily accepted. A full range of examination and investigation has been completed, the only abnormality being a mild trigonitis of uncertain clinical importance. The last letter from the consultant was received six weeks ago and, so far as we can discover, the patient has not been in touch with the practice by phone or in person since. It seems that everybody has won this time.

\section{Discussion document on ethical responsibilities of doctors practising in National Health Service}

\section{JOINT WORKING PARTY OF THE CONFERENCE OF MED ICAL ROYAL COLLEGES AND THEIR FACULTIES IN THE UK AND THE BRITISH MEDICAL ASSOCIATION}

British Medical fournal, 1977, 1, 157-159

Representatives of the Conference of Medical Royal Colleges and their Faculties in the United Kingdom and of the British Medical Association have, as a joint working party, discussed the ethical responsibilities of the medical profession in the context of a national health service. It was clear to both bodies independently that the increasing involvement of the State in matters of health care poses several ethical problems that have not previously been adequately examined.

In this report the working party has tried to identify the major dilemmas and uncertainties and to suggest some ethical criteria. These suggestions are in no way intended to reflect the official policies of the constituent bodies represented on the working party, nor should they be regarded as an attempt to dictate to others. But it is hoped that doctors will accept this document as a basis for thought and discussion and that even-

The following members have served on the working party:

Sir Rodney Smith, KBE, PRCS (chairman).

Representing the Conference of Medical Royal Colleges and their Faculties in the United Kingdom:

Professor Sir Cyril Clarke, KBE, PRCP, FRS; Mr James Ross, MBE (past president, RCS, Edinburgh); Professor John Crofton (past president, RCP, Edinburgh); Sir Ferguson Anderson, OBE (past president, RCPS, Glasgow); Dr J Badenoch, FRCP; Professor P S Byrne, CBE (past president, RCGP); Dr E V Kuenssberg, CBE, PRCGP.

Representing the British Medical Association:

$\mathrm{Mr}$ Walpole Lewin, FRCS (immediate past chairman of Council); Dr J C Cameron, CBE, FRCGP (chairman of Council); Mr David E Bolt, FRCS; Dr John S Happel, FRCGP (chairman of Central Ethical Committee); Dr J N Johnson, MB, ChB (member of Hospital Junior Staffs Committee).

Joint secretaries:

Dr John Havard, MD, LLB (deputy secretary, British Medical Association); Mr R S Johnson-Gilbert, OBE, MA (secretary, Royal College of Surgeons of England). tually some principles will emerge that will be widely accepted, though in matters of ethics it would be unreasonable to expect unanimous conclusions.

\section{Principles}

The working party believes that the following principles are worthy of general acceptance.

(1) The ethical obligations of an individual doctor to a patient under his active clinical care are absolute and inescapable.

(2) Since everybody is a potential patient, a doctor's ethical obligations to those who are not already under active clinical care cannot be so clearly defined or agreed. If it is accepted that the medical profession itself has a general obligation to the community, the one certainty is that this does not exist in isolation. If the State has undertaken to provide health care for the community, it too has obligations, both to the medical profession and to the community. It is also responsible for defining the limits of the health care to be provided in a government service and for making available the resources, both physical and human, for its delivery.

(3) As a near-monopoly employer of doctors, the State clearly has a special obligation to ensure that professional ethics are not brought in conflict with doctors' contractual obligations. The imposition on doctors of legal obligations incompatible with ethics would compel them to leave the National Health Service in order to practise independently.

(4) If the State ever became a monopoly employer and forbade independent practice, even this option would be denied to doctors. In this situation, if the State were to impose obligations incompatible with ethics, there would be no way at all that a doctor could protect his patients and insist that their interests must come first. This would be disastrous for the community in general as well as for the profession of medicine.

(5) If a dispute between the profession and the State as a nearmonopoly employer cannot be resolved, each individual doctor must continue to rely on his own conscience to determine his ethical obligations and must continue to be guided by these in the actions he may take.

(6) Government has a special obligation to establish machinery acceptable to doctors that will prevent or resolve disputes that may lead to a conflict of obligations. The present machinery has proved inadequate, and a more effective means of conciliation is required. 